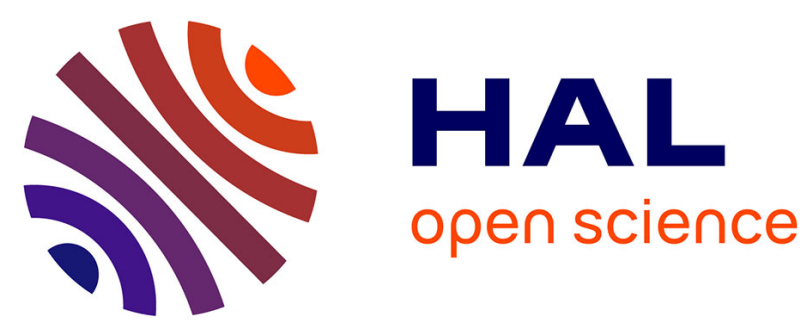

\title{
Numerical modelling of moisture transfers with hysteresis in cementitious materials: Verification and investigation of the effects of repeated wetting-drying boundary conditions
}

\author{
Zhidong Zhang, Mickaël Thiery, Véronique Baroghel-Bouny
}

\section{To cite this version:}

Zhidong Zhang, Mickaël Thiery, Véronique Baroghel-Bouny. Numerical modelling of moisture transfers with hysteresis in cementitious materials: Verification and investigation of the effects of repeated wetting-drying boundary conditions. Cement and Concrete Research, 2015, 68, pp.10 - 23. 10.1016/j.cemconres.2014.10.012 . hal-01622016

\section{HAL Id: hal-01622016 \\ https://hal-enpc.archives-ouvertes.fr/hal-01622016}

Submitted on 23 Oct 2017

HAL is a multi-disciplinary open access archive for the deposit and dissemination of scientific research documents, whether they are published or not. The documents may come from teaching and research institutions in France or abroad, or from public or private research centers.
L'archive ouverte pluridisciplinaire HAL, est destinée au dépôt et à la diffusion de documents scientifiques de niveau recherche, publiés ou non, émanant des établissements d'enseignement et de recherche français ou étrangers, des laboratoires publics ou privés. 


\title{
Numerical modelling of moisture transfers with hysteresis in cementitious materials: verification and investigation of the effects of repeated wetting-drying boundary conditions
}

\author{
Zhidong ZHANG ${ }^{\mathrm{a}, \mathrm{b}}$, Mickaël THIERY ${ }^{\mathrm{b}, \mathrm{c}}$, Véronique BAROGHEL-BOUNY ${ }^{\mathrm{b}}$ \\ ${ }^{a}$ Department of Civil and Environmental Engineering, Princeton University, Princeton, NJ 08544, USA \\ ${ }^{b}$ Paris-Est University, IFSTTAR, MaSt/FM ${ }^{2} D$, F-77447 Marne-la-Vallée, France \\ ${ }^{c}$ DGAC, STAC, F-94385 Bonneuil-sur-Marne, France
}

\begin{abstract}
In natural environment, the cover layer of reinforced concrete structures is affected by periodic variations of external relative humidity $(\mathrm{RH})$. However, most moisture transport models in the literature only focus on drying of materials. In this study, a method coupling a moisture transport model with any kind of hysteresis modelling is presented. Two hysteresis models (conceptual and empirical) have been implemented and compared. The scope of the study is limited to cyclic variations of RH with no direct contact with liquid water during the wetting steps. Experimental data verifications show that the conceptual approach yields better results than the empirical one. Comparisons of non-hysteresis and hysteresis modellings have been carried out for different cycle durations, RH amplitudes and initial moisture states. All comparisons and investigations enhance the necessity of considering hysteresis to quantify moisture transport under repeated drying-wetting boundary conditions.
\end{abstract}

Keywords: cementitious materials (E), moisture transport (C), hysteresis (C), drying-wetting cycles (A), moisture penetration depth (B)

\section{Introduction}

The durability of reinforced concrete structures is closely related to environmental conditions. External conditions are various, including drying action of wind and sun, wetting from rain-water and spray, freezing and thawing actions, etc. The movement of liquid-water and the diffusion of gas or ions are the essential transport phenomena which govern durability of concrete. Most of the mechanisms of degradation (chloride ingress, carbonation, corrosion, etc.) are highly influenced by the moisture state of the material. To evaluate the durability of concrete structures, it is hence extremely useful to study moisture interactions between the cementitious materials and the environment.

In the literature, modelling of moisture transport in cementitious materials generally focuses on the drying process caused by low ambient RH (e.g., [1]). However, the natural environment dose not only correspond to drying conditions. Drying and wetting appear alternatively in natural conditions. This is considered as the most unfavourable environmental situation for concrete structures exposed to high ions content surroundings, because drying and wetting cycles can accelerate the penetration of ions (e.g., chlorides [2]). Therefore, to understand durability issues, there is a need to model moisture behaviour under drying and wetting cycles. Let's bear in mind that the terms "drying" and "wetting" used here refer to moisture transport occurring in the hygroscopic range. In other words, the present study only considers the material exposed to the humid air with no direct contact with liquid-water.

For modelling of moisture transport using a continuum model [3], the water vapor sorption isotherms (WVSIs) [4], describing the relationship between RH (or capillary pressure $P_{c}$ ) and water content $\theta$ (or degree of saturation $S$ ), are generally used. Modelling of drying process normally employs the main desorption curve [1] while modelling of wetting or re-drying processes is more complicated because of sorption hysteresis. Sorption hysteresis is illustrated as a difference in water content for a same RH value (see the saturation differences for the same RH in Fig. 1). Previous models generally neglect hysteresis and use the main desorption isotherm to model moisture transport for both drying and wetting processes (e.g, [5]) ; it might be due to the lack of experimental data for verification and premature computation techniques. 
More recently, modelling considering hysteresis has become a topic of interest. Johannesson and Nyman [6,7] and Johannesson and Janz [8] have adopted empirical hysteresis models in which each scanning isotherm is expressed by a polynomial function. The independent domain theory model (Preisach-Mayergoyz PM model [9, 10]), which was initially developed for modelling of physical mechanisms of magnetization, has been employed in the research performed by Derluyn et al. [11]. These studies have emphasised the necessity of considering hysteresis for predicting moisture behaviour in cementitious materials. Derluyn et al. [11] concluded "durability risks may be underestimated when omitting moisture hysteresis". Johannesson et al. [7] even argued that "the error in determining the water content may be as high as 30-35\%" for the non-hysteresis modelling.

Nonetheless these conclusions have been only verified thanks to limited supporting experimental data which generally correspond to sorption measurements carried out on thin samples and for small RH steps. According to the authors, there are no real comparisons in the literature between simulations and mass loss kinetics and/or moisture content profiles showing the effects of repeated drying and wetting boundary conditions on specimens whose size are representative of the concrete cover thickness. The present study provides experimental data (desorption and adsorption isotherms, mass loss curves and liquid-water saturation profiles) for three materials to verify and compare the proposed models. Moreover empirical and conceptual models are separately used in studies provided by Johannesson and Nyman [6, 7], Johannesson and Janz [8] and Derluyn et al. [11]. Thus a comparison of these two kinds of models with the same set of experimental data is needed to investigate the differences between them.

One important factor to evaluate the durability of concrete structures under repeated drying-wetting corresponds to the moisture penetration depth $x_{p}$ which is of major importance for engineers. This factor is used to quantify how deep moisture variations can influence the material; it represents the depth that ions can reach into the material under drying-wetting cycles and is thus particularly important for the description of ions penetration. Previous researches have concluded that $x_{p}$ is dependent on the material properties (porosity, diffusivity coefficient, etc.), the cycle duration and the external RH amplitude [12]. Nevertheless, this conclusion was based on non-hysteresis modelling. Results in the case of hysteresis modelling have not been studied yet. The present paper is going to provide such investigations.

The purpose of this paper is to find an appropriate modelling of moisture transfers which can be used to simulate various ambient humidity loads and which is enough flexible to be performed with any kind of hysteresis description. Different approaches of modelling will be studied through comparisons with experimental data for verification. In the first part, commonly-used hysteresis models will be briefly introduced, and then a continuum moisture transport model will be described. A method to incorporate hysteresis models within a moisture transport model will be proposed. Experimental data, including mass loss curves and saturation profiles, will be used to verify the proposed method. Modelling results based on non-hysteresis and hysteresis modellings (empirical and conceptual) will also be compared. Then, effects of the drying and wetting cycle duration, RH amplitude and initial state will be discussed. The last part will investigate the moisture penetration depth performed with non-hysteresis and hysteresis modellings.

\section{Modelling of hysteresis}

The response of a concrete to repeated cyclic wetting-drying boundary conditions depends on its sorption behaviour represented by the de- or adsorption isotherms which are defined as the mass of physically bound water held in a material with respect to RH at a specific temperature. The desorption isotherm relates the water saturation state to the relative humidity if $\mathrm{RH}$ is decreasing. If $\mathrm{RH}$ is increasing, the evolution of the water content of the material is related to surface adsorption of water molecules and capillary condensation. When RH increases from a low value, surface adsorption occurs first since water vapour molecules begin to adsorb on the pore walls; it corresponds to one-layer adsorption followed by multi-layers adsorption. Beyond $60 \% \mathrm{RH}$ in the case of cement-based materials, the increase of RH is followed by capillary condensation [4].

Whereas the process of drying of a porous material leads to an equilibrium curve commonly called desorption isotherm, there is not a real consensus about the way to name the process of liquid-water uptake in a cement-based material. Some authors use the term "adsorption" by generalizing the IUPAC nomenclature (International Union of Pure and Applied Chemistry) $[13,14,15]$ and by including surface adsorption and capillary condensation together in the same definition $[16,4,17,18,19]$. Other authors prefer using the term "sorption" to represent the uptake of water molecules [20, 21]. Finally, there are authors who opt for "absorption" to refer exactly to the same definition $[22,23,24]$. These latter make this choice to avoid any confusion between surface adsorption and capillary condensation, especially if models (for instance BJH, Barret, Joyner and Halenda, [25]) are used to investigate the pore 
size distribution of a porous material thanks to a distinction between surface adsorption and capillary condensation phenomena. In the present research, we made the choice of using "adsorption" in compliance with previous works performed by the authors of the present research. Moreover water vapor sorption data are not used here to investigate microstructure properties.

According to previous studies [26], hysteresis models of the sorption behaviour are roughly divided into two groups: conceptual and empirical models. The conceptual models were developed on the basis of domain theories, such as dependent and independent domain theories [9, 27, 28, 29]. The empirical models were based on fitting the shapes of experimental scanning curves to determine the parameters of these models $[7,8,30,31,6]$. Our comparisons [26] showed that empirical models provide better results for the prediction of the first scanning curves thanks to additional parameters. However, the non-physical "pumping effect", generally related to the use of empirical models and referring to the non-closed form of the scanning loops, remains problematic [32,33]. On the contrary, conceptual models can inherently avoid this non-physical behaviour. In this study, both conceptual and empirical hysteresis models will be implemented to compare their effects on moisture transport.

\subsection{The conceptual hysteresis model - Mualem Model II [34]}

Mualem Model II [34] is one of the typical independent domain models. It was developed based on the "similarity hypothesis" proposed by Philip [35]. According to Mualem's diagram [34], two basic pore water distribution functions $L$ and $H$ are used to calculate a scanning curve:

$$
L\left(P_{c}\right)=S_{w} \quad H\left(P_{c}\right)=\frac{S_{d}-S_{w}}{1-S_{w}}
$$

where $S_{w}=S_{w}\left(P_{c}\right)$ is the saturation of the main adsorption curve and $S_{d}=S_{d}\left(P_{c}\right)$ is the saturation of the main desorption curve. After a certain number of drying and wetting cycles (let's define this number as $N$ ), the expression for the wetting scanning curve is written as:

$$
S_{N, w}\left(P_{c}\right)=S\left(P_{c, N}\right)+\left[L\left(P_{c}\right)-L\left(P_{c, N}\right)\right]\left[1-H\left(P_{c, N}\right)\right] \text { for } L\left(P_{c}\right) \leq L\left(P_{c, N-1}\right)
$$

where $P_{c, N}$ and $S\left(P_{c, N}\right)$ represents the capillary pressure and the saturation at the starting point of the current scanning curve, respectively. Similarly, $P_{c, N-1}$ and $S\left(P_{c, N-1}\right)$ represents capillary pressure and saturation at the starting point of the previous scanning curve, respectively. If $L\left(P_{c}\right) \geq L\left(P_{c, N-1}\right)$, Mualem's model [34] indicates that $L\left(P_{c, N-3}\right)$ will be used to take the place of $L\left(P_{c, N-1}\right)$ until the wetting scanning curve reduces to the main adsorption curve (when $N=0$ ). In the same manner, the expression for the drying scanning curve after the $N$ th drying and wetting switch is written as:

$$
S_{N, d}\left(P_{c}\right)=S\left(P_{c, N}\right)-\left[L\left(P_{c, N}\right)-L\left(P_{c}\right)\right]\left[1-H\left(P_{c}\right)\right] \text { for } L\left(P_{c}\right) \geq L\left(P_{c, N-1}\right)
$$

If $L\left(P_{c}\right) \leq L\left(P_{c, N-1}\right), L\left(P_{c, N-3}\right)$ will be used instead of $L\left(P_{c, N-1}\right)$ for calculation.

Compared to the original accumulative equations in [34], Eqs. (2) and (3) are much simpler and easier for the practical application. If both main sorption curves (desorption and adsorption) are known, functions $H$ and $L$ can be achieved, and then scanning loops can be calculated.

\subsection{Empirical hysteresis model - Improved Rubin's model [36, 26]}

Rubin [36] proposed a formula to calculate the drying scanning curve. However this formula does not take into account the position of the starting point. Thus, it can not be used to simulate scanning loops. An improvement was introduced in [26] in which the equation for the drying scanning curve is expressed as:

$$
P_{c}(S)=P_{c, d}(S)-\left[P_{c, d}(S)-P_{c}\left(S_{1}\right)\right] \exp \left[\gamma_{d}\left(S-S_{1}\right)\right]
$$

where $S_{1}$ is the saturation at the starting point of a scanning curve, $\gamma_{d}$ is a material constant, $P_{c}(S)\left(P_{c, d}(S)\right.$, resp. $)$ is the capillary pressure on the scanning curve (the main desorption curve, resp.) corresponding to the current saturation $S$ and $P_{c}\left(S_{1}\right)$ is capillary pressure of the starting point of the current scanning curve. The negative value of $\gamma_{d}\left(S-S_{1}\right)$ limits the exponential expression from 1 (at the starting point) to near 0 (almost on the main curve). Similarly, the expression for the wetting scanning curve is derived as: 


$$
P_{c}(S)=P_{c, w}(S)+\left[P_{c}\left(S_{1}\right)-P_{c, w}(S)\right] \exp \left[\gamma_{w}\left(S_{1}-S\right)\right]
$$

The constant $\gamma_{d}$ and $\gamma_{w}$ are used to adjust the shape of the scanning curve and needs to be determined by means of experimental data (drying or wetting kinetics, moisture profiles, etc.).

It is clear that both hysteresis models (conceptual and empirical) require the main desorption and adsorption curves to calculate the scanning loops. The equation for the fitting of the main de-ad-sorption curves will be provided in the next section.

\section{Continuum approach of moisture transport in unsaturated porous materials}

If the porous medium is viewed at a macroscopic level, the solid skeleton can be assumed to be rigid. Research results have shown that main transport mechanisms in an unsaturated low-permeable porous media like cement-based materials are mainly governed by the transport of liquid-water and the diffusion-advection of water vapor and dry air $[1,3]$. The mass balance equation of a porous material submitted to moisture transfers can be written in the following way:

$$
\frac{\partial\left[S \rho_{l}\right]}{\partial t}+\frac{\partial\left[(1-S) \rho_{v}\right]}{\partial t}+\frac{\partial\left[(1-S) \rho_{a}\right]}{\partial t}=\frac{1}{\phi} \operatorname{div}\left(\mathbf{w}_{l}+\mathbf{w}_{v}+\mathbf{w}_{a}\right)
$$

where $\rho_{l}, \rho_{v}$ and $\rho_{a}\left(\mathrm{~kg} \cdot \mathrm{m}^{-3}\right)$ are the densities of liquid water, water vapor and dry air, respectively. $\phi$ is the porosity of the porous material. $\mathbf{w}_{l}, \mathbf{w}_{v}$ and $\mathbf{w}_{a}$ are the fluxes of liquid water, water vapor and dry air, respectively.

The density of liquid-water is much higher than the density of the gaseous phase, so that the second and the third term of the left-hand side of Eq. (6) can be neglected. According to Coussy et al. [1,3] on the basis of an asymptotic analysis, the contribution of the flux of dry air in the total flux $\mathbf{w}_{l}+\mathbf{w}_{v}+\mathbf{w}_{a}$ is very weak. Furthermore, considering that the liquid phase remains incompressible, the mass balance equation is simplified in the following form which represents a simplified form of the mass balance equation related to moisture:

$$
\rho_{l} \frac{\partial S}{\partial t}=\frac{1}{\phi} \operatorname{div}\left(\mathbf{w}_{l}+\mathbf{w}_{v}\right)
$$

There exists an approach of modelling liquid-water transport in porous media having a fine microstructure (wood, concrete, soils, etc.) which relies on a separate description of the movement of free water owing to the action of capillary pressure gradient (according to Darcy's law) and a mechanism of sorption-diffusion of bound water molecules according to a diffusive process supplied by a gradient of bound water [37, 38]. This approach has a major shortcoming which relies on a tricky identification of both the transport coefficients related to bound water (diffusion coefficient) and those related to capillary movement of free water according to the Darcy law (permeability, viscosity, etc.). Furthermore, it is necessary to distinguish bound water from capillary free water which can be surrounded by strong uncertainties. An alternative idea is to extend the use of the Darcy law for bound water [39]. For instance, in the case of wood, the use of a generalized form of the Darcy law has been proposed for transport of bound water through the film-flow theory: "this assumption seems reasonable if few molecule layers adsorbed on the skeleton are sufficient to enhance the development of thick enough films in corners and surface roughness able to ensure capillary transfer, although slower than in the case of free water" [40]. A stronger hypothesis is made here since we encompass in $\mathbf{w}_{l}$ both contributions of capillary viscous movement of free water and of transport of physically-adsorbed water molecules in a single Darcy relation where capillary pressure and relative permeability are derived from the sorption curves over the whole range of RH $(0-100 \%)$ through a unique liquid-water saturation. Moreover the viscosity corresponds to the one of pure water for both free water and bound water.

The driving force for liquid transport is the gradient of liquid pressure $P_{l}(\mathrm{~Pa})[1,41]$ :

$$
\mathbf{w}_{l}=-\rho_{l} \frac{K_{0} k_{r l}(S)}{\eta} \operatorname{grad} P_{l}
$$

where $k_{r l}(S)$ represents the relative permeability, $\eta\left(\mathrm{Kg} \cdot \mathrm{m}^{-1} \cdot \mathrm{s}^{-1}\right)$ is the liquid-water dynamic viscosity and $K_{0}\left(\mathrm{~m}^{2}\right)$ is the "intrinsic" permeability to liquid-water. The intrinsic permeability can be fitted from a drying experiment. 
The flux of vapor $\mathbf{w}_{v}$ is decomposed in two terms: the first component corresponds to the diffusion contribution and the second to the advective one [1]. If assuming that the gas pressure in the material remains almost constant (equal to the atmospheric pressure), it means that the advective contribution can be neglected $[1,42]$. Thus, $\mathbf{w}_{v}$ is written as:

$$
\mathbf{w}_{v}=-D_{v 0} f(S, \phi) \operatorname{grad} \rho_{v}
$$

where $D_{v 0}\left(\mathrm{~m}^{2} \cdot \mathrm{s}^{-1}\right)$ is the free vapor diffusion coefficient in the air. The parameter $f(S, \phi)$ represents the resistance factor for gaseous diffusion ; it is related to the connectivity and tortuosity of the pore network.

In this moisture transport model, the thermodynamic equilibrium between the liquid and vapor is assumed. The equilibrium state is governed by Kelvin's law which is written in the following form:

$$
P_{c}=-\frac{\rho_{l} R T}{M_{v}} \ln \mathrm{RH}
$$

where $R=8.314 \mathrm{~J} \cdot \mathrm{K}^{-1} \cdot \mathrm{mol}^{-1}$ is the gas constant, $T(\mathrm{~K})$ is the absolute temperature and $M_{v}$ is the molar mass of water molecule $\left(\mathrm{kg} \cdot \mathrm{mol}^{-1}\right)$. Capillary pressure in the macroscopic scale is defined as the difference between the gas pressure and the liquid phase pressure $\left(P_{c}=P_{g}-P_{l}\right)$. The relationship of $P_{c}$ as a function of $S$ is known as the capillary pressure curve. For cementitious materials, this curve is indirectly measured by means of sorption experiments performed at constant temperature (so-called water vapor sorption isotherms) [4]. Various equations can be found in the literature to describe the main sorption isotherms. One well-known equation was proposed by van Genuchten [43],

$$
P_{c}(S)=a\left(S^{-1 / m}-1\right)^{1-m}
$$

where $a(\mathrm{~Pa})$ and $m$ are two fitting parameters.

The flux boundary condition (also known as convective condition [44]) is used to account for an imperfect moisture transport between the environment and the surface of the material. The expression is given as [45]

$$
q=\mathbf{w}_{l}+\mathbf{w}_{v}=\phi S_{0} E f(v)\left(P_{v}^{0}-P_{v}^{e}\right)
$$

This boundary condition includes a material property (porosity $\phi$ ), a parameter related to the environment (external vapor pressure $\left.P_{v}^{e}\right)$, the moisture state within the material near the surface $\left(P_{v}^{0}\right.$ and its related liquid-water saturation $S_{0}$ ) and the interaction between the ambient environment and the material (through the emissivity $E$ and the function $f(v)$ depending on the wind velocity $v$ ). The term $\phi S_{0}$ takes into account the reduction of wet surface when exposed to the environment. The emissivity $E\left(\mathrm{~kg} \cdot \mathrm{m}^{-2} \cdot \mathrm{s}^{-1} \cdot \mathrm{Pa}^{-1}\right)$ has been assessed from experiments which proposed a value around $2.6 \times 10^{-8} \mathrm{~kg} \cdot \mathrm{m}^{-2} \cdot \mathrm{s}^{-1} \cdot \mathrm{Pa}^{-1}[46,45]$ for a laboratory environment where $\mathrm{RH}$ and temperature are maintained constant (atmospheric pressure, $\mathrm{RH}=50 \pm 5 \%$ and $T=293 \mathrm{~K}$ ). Since the present study only considers conditions without wind effects (the samples are submitted to drying or wetting conditions in a desiccator), it is reasonable to assume that $f(v)=1$. Moreover note that the same value of $E$ is fixed for both drying and wetting modelling.

Putting Eqs. (8) - (11) back into the mass balance equation Eq. (7), and combining the initial and boundary conditions (see Eq. 12), the moisture transport problem can be solved. It also should be noticed that Eq. (11) is used for the main sorption curve. In the case of modelling with hysteretic effects, a hysteresis model is needed to calculate a new $P_{c}-S$ relation (see section2).

\section{Modelling methods}

\subsection{Numerical method}

To solve the non-linear equations, a numerical algorithm has to be used. The spatial discretization is performed by a finite difference method which is relevant since only a 1-D problem is considered in this study. An implicit approximation (backward Euler method) in time step is employed to ensure the stability of the scheme. In each time step, the Picard iterative scheme is used to reach the numerical convergence criteria [47]. The time step is adaptive according to the convergence rate to solve the partial differential equation efficiently. 


\subsection{Modelling without hysteretic effects}

Modelling of moisture transport without hysteretic effects can be easily achieved by using the same sorption isotherm for both drying and wetting. Generally, the main desorption curve is used $[12,5,11]$. This method has proved that simulation results do not agree with experimental data for the wetting process [42]. A new expression for sorption curves is proposed here on the basis of the measured main desorption and main adsorption curves involving a weighting factor $\omega \in[0,1]$ :

$$
S=\omega S_{d}+(1-\omega) S_{w}
$$

In Eq. (13), $\omega=1$ corresponds to the main desorption curve; if $\omega=0$, the main adsorption curve is used, and if $\omega=0.5$ the sorption curve is the average curve. The parameter $\omega$ increases the flexibility of the use of this nonhysteresis modelling method.

\subsection{Modelling with hysteretic effects}

In order to incorporate a hysteresis model to simulate drying and wetting cycles, two issues need to be solved: how to check whether the node is going to change the state, and how to keep the node on the current state? Inspired by the work of Gillham et al. [48], two hysteresis indexes $U$ and $V$ are introduced to deal with each issue. These two indexes have to be assigned to each node during the numerical calculations.

The index $U$ is used to mark the current state. The initial values of $U$ for all nodes are zero. If the initial step of a node is drying (the case of initial drying), $U$ will be 0 until the next state change. If the initial step is wetting (initial wetting), $U$ must be assigned as 1 . For the first node (the node on the surface of the material), the initial step can be determined by the sign of the RH difference between the boundary condition and the initial condition. The negative sign means initial drying, and the positive sign means initial wetting. For inner points, the initial step will be given during the numerical calculations. In the calculation, $U$ will be added by 1 after each state change. So, the even numbers of $U$ represent that the node is currently on the drying process and the odd numbers stand for the wetting process.

The hysteresis index $V$ is set as 0 at the beginning of the calculation. This index is used to notify the programme if one node has to change its state in next time step through checking whether the current state is consistent with the sign of the saturation difference between the current step and the previous step, $\Delta S(i)$. If $\Delta S(i)$ is smaller than a given criterion, such as $10^{-10}$ in the present study, but the current state is wetting ( $U$ is an odd number), this means that the node will become drying; so then $V$ is set as -1. If $\Delta S(i)$ is bigger than the criterion, but the current state is drying ( $U$ is an even number), this implies that the node is going to be wetting, and then $V$ is assigned to 1 . If there is no state change for the next time step, $V$ must be 0 .

The combinations of these two indexes $V$ and $U$ are able to represent all states for each node during arbitrary drying and wetting cycles. After a given number of cycles, index $U$ can tell how many drying or wetting steps have occurred at one given node, and on which the $N$ th drying or wetting scanning is. This is very useful for hysteresis modelling due to the strong sorption history-dependence.

Figure 1 demonstrates the use of these two indexes for one node. In natural conditions, the reinforced concrete cover is nearly saturated after formwork removal and then exposed to a low RH environment which induces drying. Thus we consider that in this process the RH-S relation starts on the main desorption curve (see point A in Fig. 1) and it will stay on this curve until the next state change. In this process, both $V$ and $U$ are zero and the programme checks if the state of this node is going to change by comparing the consistency between $\Delta S$ and $U$ in each time step. If point B is where RH increases, $\Delta S$ should be positive, but $U$ is still an even number, so the programme must assign $V$ as 1 to tell that the node will turn to wetting. After the state change, $V$ has to become 0 again. The scanning curve $\mathrm{BC}$ is used instead of the main desorption curve for this node. At the same time, $U$ increases to 1 to note that the node is on the first wetting scanning curve. In a similar way, when the state change occurs at point $\mathrm{C}, V$ becomes -1 to show that this node will be on drying in the next time step, and $U$ increases to 2 to record the second drying scanning curve. In this way, the calculation can be continued.

In this implementation method, reverse states (starting points of scanning curves) for each node have to be recorded, either for conceptual or empirical models. The programme can distinguish which state the node is on and continue the calculation through the combinations of these two indexes. For most hysteresis models, it is obviously easy to obtain reverse points for all nodes, so this method has a high applicability. 


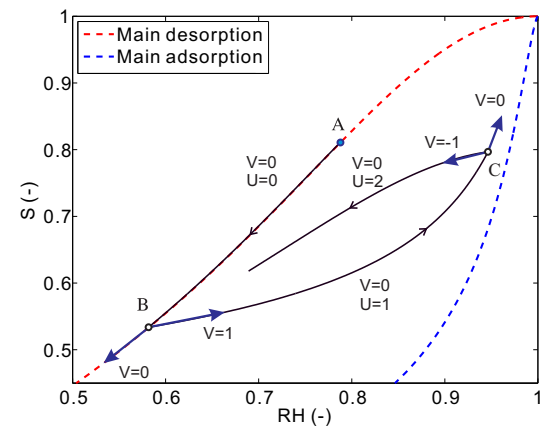

Figure 1: Implementation of the hysteresis models.

Table 1: Properties of materials and their $K_{0}$ calibrated by measured data from drying.

\begin{tabular}{lllllll}
\hline \multicolumn{2}{c}{ Materials w/c } & \multicolumn{2}{c}{ Porosity Initial } & $\begin{array}{l}\text { Drying } \\
\text { duration }\end{array}$ & $\begin{array}{l}\text { Wetting } \\
\text { duration }\end{array}$ & $\begin{array}{l}K_{0} \\
\left(\times 10^{-21} \mathrm{~m}^{2}\right)\end{array}$ \\
\hline Paste1 & 0.35 & 0.31 & 83 & 157 days & 243 days & $0.46^{1}\left(0.3^{2}\right)$ \\
Paste2 & 0.45 & 0.41 & 89 & 370 days & 315 days & $1.9^{1}$ \\
Paste3 & 0.60 & 0.49 & 95 & 370 days & 315 days & $22.0^{1}$ \\
\hline
\end{tabular}

Overall, three modelling methods, including two hysteresis models (Mualem Model II, improved Rubin's model) and the non-hysteresis modelling, can be used to simulate drying and wetting cycles. They will be compared in next section.

\section{Experimental data verifications}

\subsection{Experimental data}

Experimental data were collected from literature [4] and [45]. Three cement pastes with different water-to-cement ratios were used to verify the proposed model. The material properties are gathered in Table 1. All materials are made from the same OPC cement (CEM I 52.5, according to EN 197-1 European standard).

The water vapor sorption isotherms, including two main curves and drying/wetting scanning curves, were measured by the saturated salt solution method. The basic principle of this method is that small crushed samples were kept in a desiccator with a constant RH by means of the saturated salt solution until mass stabilization had been reached, and then the measurement could be switched to next RH. The relative humidity stepwise decreases from $\sim 100 \%$ to $3 \%$ to obtain the main desorption curve. The inverse procedure was used to measure the main adsorption curve. The detailed description of the measurements has been reported in reference [4].

Cylindrical specimens were prepared to check the validity of the model. The materials were cast in cylindrical moulds with a $7 \mathrm{~cm}$-diameter. Before experiments, cement pastes have been sealed for curing during more than 200 days. After the moulds had been removed, materials were cut into around $10 \mathrm{~cm}$-length specimens, and then these cylinders were sealed by self-adhesive aluminium foil sheets, but only one side was open for moisture exchanges with the ambient environment (see Fig. 2). All specimens were firstly stored in desiccators for drying experiments at a room temperature $\left(T=23 \pm 0.1{ }^{\circ} \mathrm{C}\right)$. $\mathrm{RH}$ was fixed at $\mathrm{RH}^{e}=53.5 \%$ by using a saturated salt solution (magnesium nitrate, $\mathrm{Mg}\left(\mathrm{NO}_{3}\right)_{2} \cdot 6 \mathrm{H}_{2} \mathrm{O}$ ). Paste1 was also submitted to drying at $\mathrm{RH}^{e}=63.2 \%$ (ammonium nitrate, $\mathrm{NH}_{4} \mathrm{NO}_{3}$ ). After drying, all specimens were exposed to $\mathrm{RH}^{e}=97 \%$ (potassium sulfate, $\mathrm{K}_{2} \mathrm{SO}_{4}$ ) for wetting. Drying and wetting durations for the different materials are presented in Table 1.

The mass loss curves were measured by weighing the specimens from time to time. Saturation profiles were measured by the gamma-ray attenuation method [49].

\footnotetext{
${ }^{1}$ Calibrated by measured data from a drying experiment at $\mathrm{RH}^{e}=53.5 \%$.

${ }^{2}$ Calibrated by measured data from a drying experiment at $\mathrm{RH}^{e}=63.2 \%$.
} 


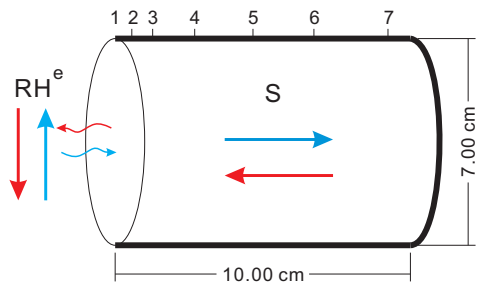

Figure 2: Schematic representation of a specimen during the drying and wetting measurement. The bold black lines represent the sealed sides of the specimen, and the ellipse in the thin line on the right-hand side represents the surface that is exposed to ambient environment. The numbers indicate the positions of nodes that are chosen to show the calculated $k_{r l}$ and $f(S, \phi)$ in Fig. 9.

Figure 3 displays the comparison of measured and predicted sorption isotherms for Paste1. Main curves are fitted by Eq. (11) and scanning curves are predicted by Mualem Model II [34] (solid scanning curves) and improved Rubin's model $[36,26]$ (dashed scanning curves). The two parameters used in improved Rubin's model are optimized to fit all measured scanning curves. They are $\gamma_{d}=5.8$ and $\gamma_{w}=24.8$ (see Eqs. 4 and 5). Due to the lack of measured scanning curves for Paste 2 and Paste3, these parameters are considered the same as for Paste1. Figure 3 shows that both hysteresis models yield similar results for the prediction of the first scanning curves, either for drying or wetting.

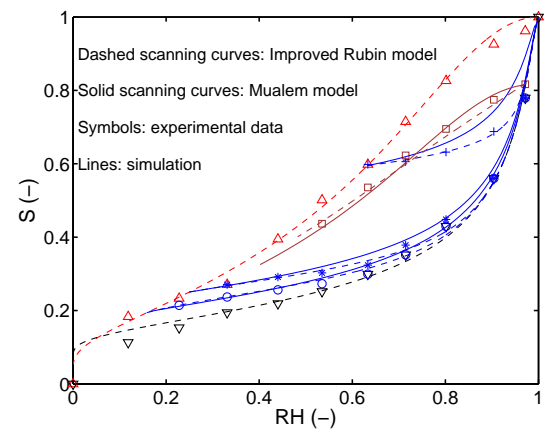

Figure 3: Simulated sorption isotherms vs. experimental data for Paste1.

\subsection{Determination of transport coefficients}

The resistance factor in Eq. (9) represents the reduction of accessibility for water vapor diffusion which is due to the presence of the solid and liquid phases, the tortuous path for diffusion, the different connectivities in the pore network, etc. Because of limited experimental results, the expression of $f(S, \phi)$ is generally derived from theoretical concepts. For example, Millington [50] deduced an equation for granular materials (soils):

$$
f(S, \phi)=\phi^{x_{D}}(1-S)^{x_{D}+2}
$$

Millington [50] proposed that parameter $x_{D}$ was fixed at 4/3. However, soils are more porous than cementitious materials, so resistance to water-vapor diffusion may be more significant for cementitious materials. Thiéry et al. [51] suggested $x_{D}=2.74$ based on the fitting of experimental data for cement pastes and mortars taken from Papadakis $e t$ al. [52]. The comparison of $f(S, \phi)$ calculated by these two proposed two values of $x_{D}$ are shown in Fig. 4 for the studied three materials. Thiéry's suggestion provides smaller resistance factor values which may be closer to the real conditions of cementitious materials compared to the original $x_{D}$ value for soils.

Another important transport coefficient is the relative permeability $k_{r l}$. The critical question about $k_{r l}$ is whether hysteresis exists in $k_{r l}(S)$. The independent domain theory provided by Poulovassilis [53] implies that $k_{r l}$ in wetting should be larger than $k_{r l}$ in drying for the same water content. This theory was supported by Mualem [54] who proposed a complicated hysteretic model for the prediction of $k_{r l}$. However, experimental data for glass-beam (a very porous material) has shown there is no hysteresis in $k_{r l}(S)$ [55]. In these later studies this conclusion was further proved 


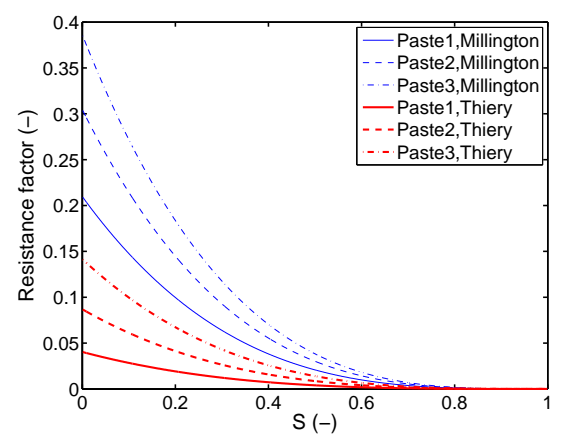

Figure 4: Predicted resistance factor $f(S, \phi)$ for the three studied cement pastes calculated by Millington's [50] and Thiéry's [51] formulas.

for sands and soils $[56,57]$. For cementitious materials, measuring the permeability to liquid-water for different RH is very difficult due to the fact that advective liquid transport and vapor diffusion always occur together; therefore, measured results include both transport mechanisms [41]. Owing to these reasons, it is acceptable to assume that $k_{r l}$ is a unique function of $S$; namely, no hysteresis in $k_{r l}(S)$ is considered. One well-known model is the van Genuchten - Mualem equation (VGM) (e.g. [58]) which was first reported by van Genuchten [43]. It is formulated as a simple analytical relation:

$$
k_{r l}(S)=S^{\ell}\left[1-\left(1-S^{1 / m}\right)^{m}\right]^{2}
$$

In Eq. (15), $m$ is the same one as in Eq. (11). The term $S^{\ell}$ is a correction factor which accounts for the influence of tortuosity. Different suggestions of parameter $\ell$ have been proposed by researchers [59, 60]. In Mualem's research, $\ell$ varies between -1 and 3 , and the value 0.5 was considered as the best choice. This value has also been used for cementitious materials $[1,61,62]$. Unlike the original integral equation proposed in [59], this analytical form of $k_{r l}(S)$ is much easier to be used for numerical modelling.

The intrinsic permeability $K_{0}$ used in Eq. (8) was determined by inversely analysing the kinetics of mass loss during a drying experiment at a constant $\mathrm{RH}$ according to the method developed in [63, 1, 64]. The initial state of modelling corresponds to the state after self-desiccation (see initial RH values in Table 1). Results of $K_{0}$ for the three studied materials are presented in the last column of Table 1 . The same values of $K_{0}$ will be used for the modelling of the wetting process (see next section). In other words, beside the boundary conditions, the only difference between modelling of drying and wetting processes is based on the use of different sorption paths.

The fitting of $K_{0}$ provides a very good agreement between the experimental mass loss kinetics determined by weighing and the simulated curves (see Fig. 6). A way to verify the relevancy of this fitting procedure is to go beyond the simple results provided by weighing and to compare simulated profiles of liquid-water saturation to profiles determined by gamma-ray attenuation (see Fig. 8). We note a satisfactory agreement. Note that the discrepancy is related both to the shortcomings of the modelling approach, as well to the fact that the gamma-ray attenuation method is not perfectly consistent with weighing results due to several assumptions made to interpret gamma-attenuation data in term of variations of liquid-water saturation: link between the amount of absorbed photons and the density of the material, necessity to carry out gamma-ray measurements on reference saturated and dry states to quantify a liquidwater saturation degree, etc. Thus on the basis of the authors' experience, we assess a relative discrepancy of 5\% between the result of integration of the gamma-ray moisture profile and the mass variation of the specimen measured by weighing.

It can be noted that there is a difference in the values of $K_{0}$ for Paste 1 fitted by using two different drying conditions on two different specimens (at $\mathrm{RH}^{e}=53.5 \%$ and $63.2 \%$, see Table 1). The mass loss curves of the drying experiment at $\mathrm{RH}=63.2 \%$ simulated by using $K_{0}$ adjusted thanks to the experiment at $\mathrm{RH}=53.5 \%$ is shown in Fig. 5 . The relative deviation does not exceed $10 \%$. Theoretically, $K_{0}$ should be independent of the external drying conditions, but the variability which affects the preparation of two different specimens of the same mix-design could contribute to justify such discrepancy. 


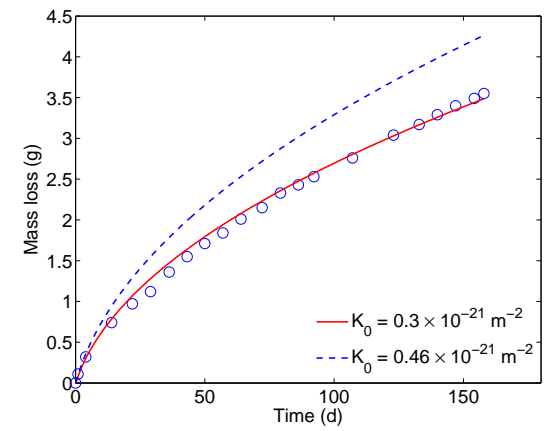

Figure 5: Comparisons of mass loss curves simulated by using two fitted different $K_{0}$ values for Paste1: (1) mass loss curve which results from the fitting of the drying experiment at $\mathrm{RH}=63.2 \%$ and (2) mass loss curve simulated by using $K_{0}$ adjusted thanks to the experiment at $\mathrm{RH}=53.5 \%$.

\subsection{Experimental verification}

Simulation results of the mass loss curves (mass loss vs. time) for Paste1 are shown in Fig. 6. Simulations performed by the non-hysteresis modelling are presented in two cases, $\omega=0.5$ and 1 which correspond to the average sorption curve and the main desorption curve, respectively. Mass loss curves measured during the drying process are used to determine $K_{0}$ : the fitting results are quite good.

Then, to evaluate the different modelling methods and the performance of the fitting of $K_{0}$, it is necessary to compare simulation results during the wetting step. Mualem Model II provides the best agreement with the measured mass loss curves for the wetting process, either for initial drying at $\mathrm{RH}^{e}=53.5 \%$ or at $63.2 \%$. Meanwhile, improved Rubin's model overestimates the total moisture mass obtained during the wetting process for both initial drying cases. Both cases of non-hysteresis modellings ( $\omega=0.5$ or 1$)$ unexpectedly provide very similar results which underestimate the mass loss and cause that mass loss curves drop sharply during wetting.

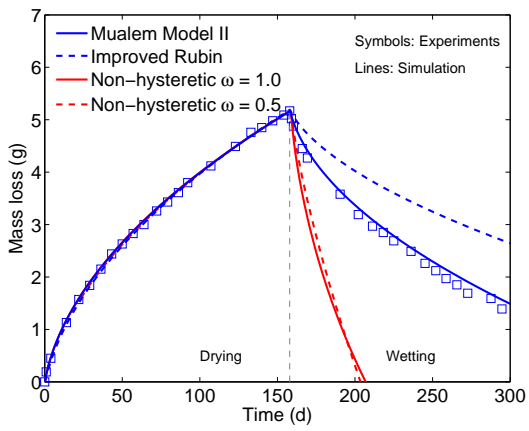

(a) Drying at $\mathrm{RH}^{e}=53.5 \%$.

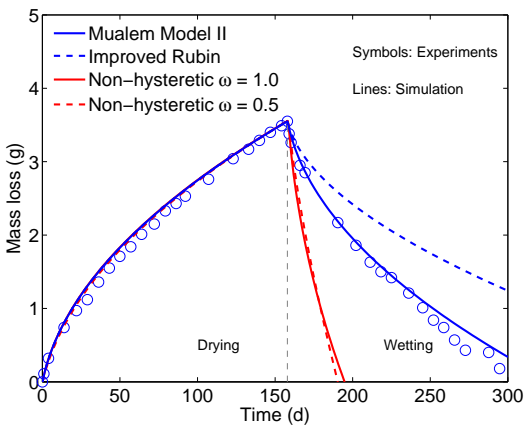

(b) Drying at $\mathrm{RH}^{e}=63.2 \%$.

Figure 6: Comparisons of mass loss curves simulated by non-hysteresis and hysteresis modellings with experimental results for Paste1.

In the same way, simulated and measured mass loss curves for Paste2 and Paste 3 are compared in Fig. 7. Saturation profiles at the end of drying and the end of wetting for these two materials are shown in Fig. 8. Even though predicted mass loss curves show a slight difference with the measured curves during the wetting processes (mainly for Paste3), Mualem Model II is still the best one which provides high agreements with experimental data. Again, the results computed by improved Rubin's model and the non-hysteresis modelling are not as good as Mualem Model II. Because both cases of non-hysteresis modelling show similar results, the case of the main desorption curve $(\omega=1)$ will be adopted to represent the non-hysteresis modelling in the following sections.

In term of saturation profiles, Fig. 8 shows that three modelling methods provide very different saturation profiles at the end of the wetting process. Results simulated by the non-hysteresis modelling are far above the measured ones (see the dashed-dotted curves in Fig. 8) which leads to around 20 - 30\% differences on the surface of the material 


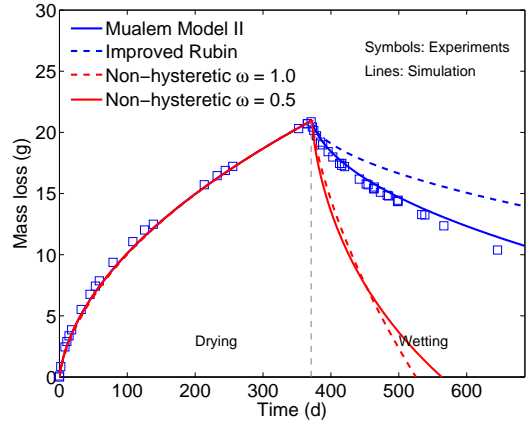

(a) Paste2.

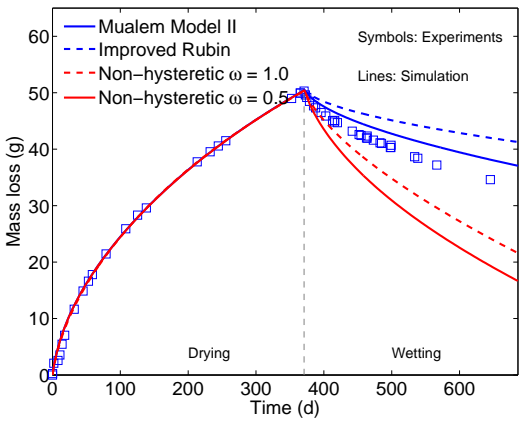

(b) Paste3.

Figure 7: Comparisons of simulated mass loss curves with experimental results for Paste2 and Paste3, drying at $\mathrm{RH}^{e}=53.5 \%$.

compared to the measured profiles. The case of using improved Rubin's model shows that saturation profiles are below the experimental data (see the dashed curves in Fig. 8). Mualem Model II obviously performs better than the others. One important reason is that $S$ provided by Mualem Model II at the boundary is much closer to the measured results than the values provided by the other modelling methods (see the boundary points in Fig. 8). More reasons will be analysed in section 5.4 .

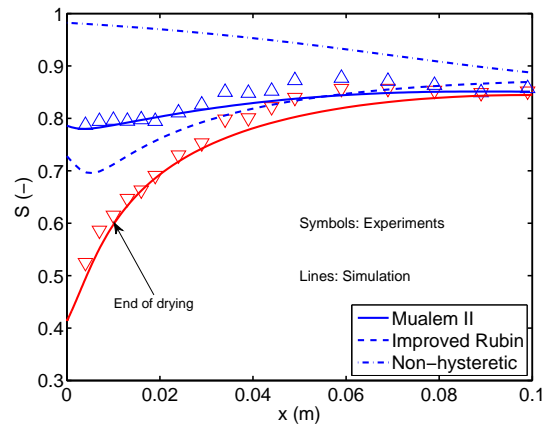

(a) Paste2

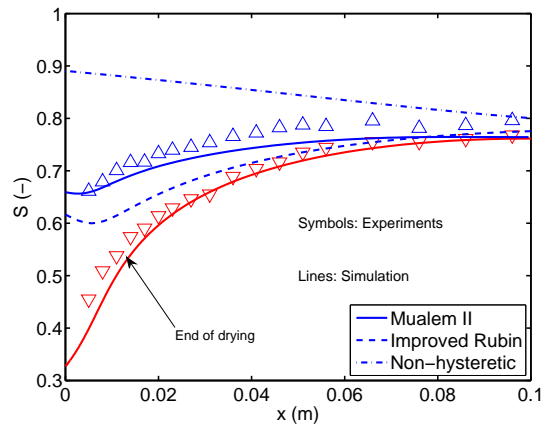

(b) Paste3.

Figure 8: Saturation profiles simulated by non-hysteresis $(\omega=1.0)$ and hysteresis modellings are compared with experimental data for Paste2 and Paste3, drying at $\mathrm{RH}^{e}=53.5 \%$ and wetting at $\mathrm{RH}^{e}=97 \%$. Red lines and inverted triangle symbols correspond simulated and measured profiles at the end of drying, respectively. Blue lines and triangle symbols correspond simulated and measured profiles at the end of wetting, respectively.

Based on verifications by the four sets of experimental data, it can be concluded that Mualem Model II is clearly more appropriate than improved Rubin's model and the non-hysteresis method to simulate repeated drying and wetting. Moreover the difference between using the conceptual model (Mualem Model II) and the empirical model (improved Rubin model) is also significant. That is mainly due to the pumping effect (denoted PE), as mentioned in section 2. PE has been widely considered as a non-physical behaviour for most porous media [32, 33]; thus PE is also called "pumping error". It is the main difference between conceptual and empirical hysteresis models [26]. Even though Johannesson and Nyman [6,7] used an empirical hysteresis model to simulate hysteresis for cementitious materials, they have realized that PE can lead to unusual mass changes in case of successive scanning loops. A comparison performed in a previous study [26] demonstrated that if the empirical model fails to eliminate PE, the cumulative errors associated with fluctuations of hysteresis loops become significant and cause non-physical behaviours.

As mentioned in section 3, there are two key transport coefficients for modelling of moisture transport ; they are the relative permeability $k_{r l}$ for the description of advective transport of liquid-water and the resistance factor $f(S, \phi)$ for water-vapor diffusion. Both transport coefficients are expressed as functions of $S$ which means that there is no hysteresis between these two coefficients and $S$. However, because of hysteresis in RH $-S$, hysteresis between these two coefficients $\left(k_{r l}\right.$ and $\left.f(S, \phi)\right)$ and RH can be observed. One example for Paste1 (drying at $\mathrm{RH}^{e}=53.5 \%$ ) is shown 
in Fig. 9. The relative permeability $k_{r l}$ monotonously increases with $\mathrm{RH}$, but $f(S, \phi)$ monotonously decreases with RH. For nodes near the surface of the material (e.g. point 1), during the wetting process $k_{r l}$ increases rapidly and $f(S, \phi)$ decreases sharply while for inner nodes (e.g. points 6 and 7) they do not have significant changes due to small RH fluctuations.

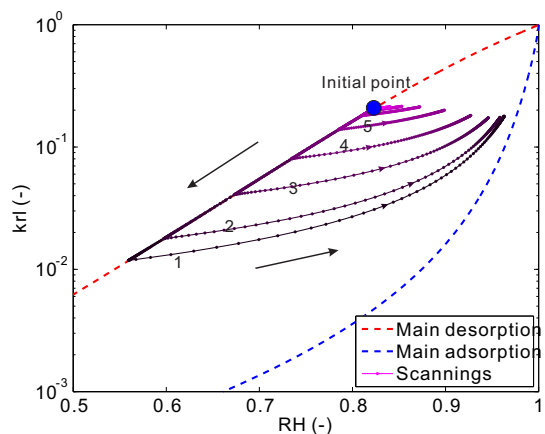

(a) Evolution of $k_{r l}$.

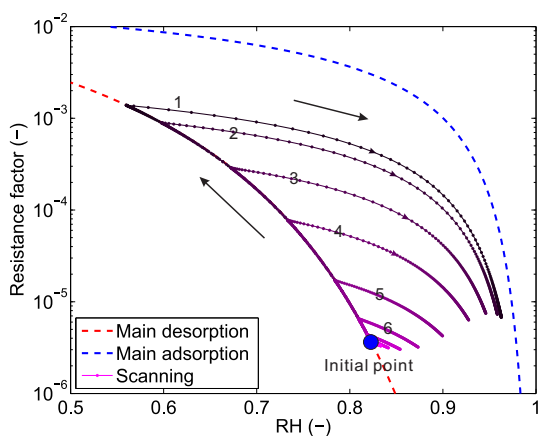

(b) Evolution of $f(S, \phi)$.

Figure 9: Evolutions of $k_{r l}$ and $f(S, \phi)$ at different depths simulated by Mualem Model II [34] for Paste1 (for the case of drying at 53.5\%). The numbers of curves corresponds to the node positions which have been marked in Fig. 2.

\subsection{Analysis of differences between non-hysteresis and hysteresis modellings}

Through comparisons with experimental data, it is clear that the non-hysteresis modelling $(\omega=1)$ yields a higher $S$ near the surface in the material during wetting than the hysteresis modelling. A figure has been drawn to explain this difference (see Fig. 10). Because the non-hysteresis modelling only uses the desorption curve, when it is switched to wetting, $S$ at the boundary will increase to the point corresponding to $\mathrm{RH}^{e}=97 \%$ on the main desorption isotherm, as shown in Fig. 10. However, due to hysteretic behaviour, the wetting boundary condition for the hysteresis modelling is much lower than the point on the main desorption curve for the same RH. This boundary condition is close to the main adsorption curve (see Fig. 10). Surprisingly, it agrees with the measured saturation at the boundary obtained by the gamma-ray attenuation method as explained in section 5.3 and illustrated in Fig. 8. The saturation difference between these two cases of wetting boundary conditions is the primary reason that causes saturation profiles simulated by the hysteresis modelling to be always lower than the ones predicted by the non-hysteresis modelling.

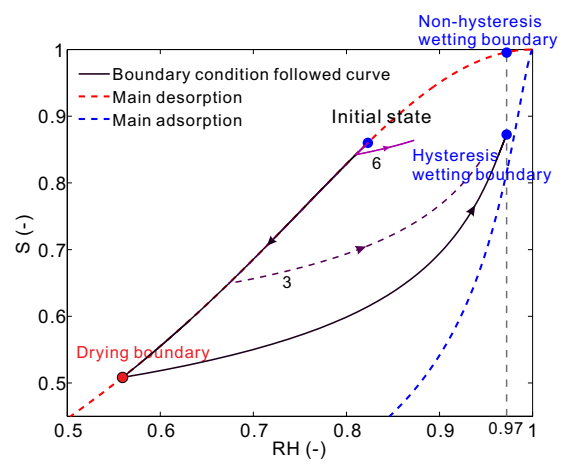

Figure 10: The differences of boundary conditions used in non-hysteresis and hysteresis modellings. Points 3 and 6 have correspond to nodes which have been shown in Fig. 2.

Moreover, Fig. 10 provides the sorption isotherm evolutions of two inner nodes (points 3 and 6). In the hysteresis modelling, these nodes always have lower $S$ values than the non-hysteresis modelling for a given RH. This directly leads to a lower $k_{r l}$ for these two points (see curves 3 and 6 in Fig. 9a). The mass transport in a low-permeable porous medium like a cement paste is mainly governed by liquid-water transport [1, 42]. Thus, the simulated mass transport 
with hysteresis is slower than that without hysteresis. As a consequence, the mass variations predicted by the hysteresis modelling during wetting is smaller than the mass variations computed by the non-hysteresis modelling (see Figs. 6 and 7). This also results in a slower increase of saturation profiles during wetting if hysteretic effects are considered (see Fig. 8).

\section{Effect of different cyclic boundary conditions}

Compared to the hysteresis modelling, the non-hysteresis modelling is much easier to implement and able to save computing time. Hence, it is worth carefully analysing the applicability of these different methods under various situations. Mualem Model II will be used as a benchmark for comparisons because it has been confirmed to be the most relevant one in comparisons with experimental data (see section 5.3).

\subsection{Effects of the drying and wetting cycle duration}

The first situation discussed is the influence of the drying and wetting cycle duration. In real conditions, RH varies daily, monthly and seasonally; so for modelling purposes, different cycle durations will be tested: 1 day, 30 days and 90 days. The simulation conditions used here are: initially $\mathrm{RH}^{0}=75 \%$, then drying at $\mathrm{RH}^{e}=53 \%$ and wetting at $\mathrm{RH}^{e}=$ $97 \%$. The same duration is used for each process (15 days). Simulation results of saturation profiles and scanning loops are shown in Fig. 11.

Obviously, the time to reach mass loss stabilization is different between both modelling methods and depends on many factors (durations of the drying/wetting cycles, boundary conditions, initial RH, etc.). For the tested case in the current section, the mass loss curve provided by the hysteresis modelling reaches equilibrium quickly while for the non-hysteresis modelling, this process needs longer time.

For 1-day cycle duration, the differences of mass loss curves calculated by these two methods are very small, as well as saturation profiles, which always fluctuate around the initial state (only the part in the vicinity of the surface is really affected). But for cycle durations of 30 and 90 days, the differences between both modelling methods are more obvious. Mass loss curves calculated by the non-hysteresis method reach very low value. These differences are also illustrated with the simulated saturation profiles. The hysteresis modelling shows similar shapes of saturation profiles for 30 and 90 days durations. For non-hysteresis modelling, the saturation profile progressively rises during the simulation. It is due to moisture moving into the material, so that the mass of the material increases gradually (see the left-hand side subfigures in Figs. 11b and 11c).

The main reason of this difference refers to the different saturation at the boundary as explained in section 5.4. The saturation for the wetting boundary conditions is remarkably inconsistent between hysteresis and non-hysteresis modellings. For the non-hysteresis modelling, saturations are 0.87 and 0.90 for 30 - and 90-day cycle durations, respectively, while for the hysteresis modelling, the boundary saturation is between 0.77 and 0.80 , which is much lower than the ones in the case of the non-hysteresis modelling. These different boundary conditions are also clearly presented in sorption isotherms (see the scanning loops for point 1 in the right-hand side subfigures of Fig. 11).

\subsection{Effects of the boundary RH amplitude}

$\mathrm{RH}$ amplitude is another factor which can significantly affect moisture transport under repeated drying and wetting cycles. In the previous discussion about the impact of the cycle duration, an RH amplitude of $44 \%$ (53\% - 97\%) has been used. Another RH amplitude is introduced here between $64 \%$ and $86 \%$; it corresponds to the half of the RH amplitude used in the previous discussion. The initial condition $\mathrm{RH}^{0}=75 \%$ is still the same and we chose a 30 -day cycle duration.

Simulated results for the proposed new RH amplitude are provided in Fig. 12. Compared to Fig 11b, the difference in the mass loss curves simulated with the hysteresis modelling in cases of these two RH amplitudes is clear. The mass loss curve slightly drops in Fig $11 \mathrm{~b}$ whereas the curve rises in Fig. 12. A more pronounced difference can even be seen with the non-hysteresis modelling. Again, the saturation difference between the drying and wetting boundary conditions is more obvious for the non-hysteresis modelling than for the hysteresis modelling as it has already been emphasized in the comparisons between simulations and experimental results (see Fig. 8). 

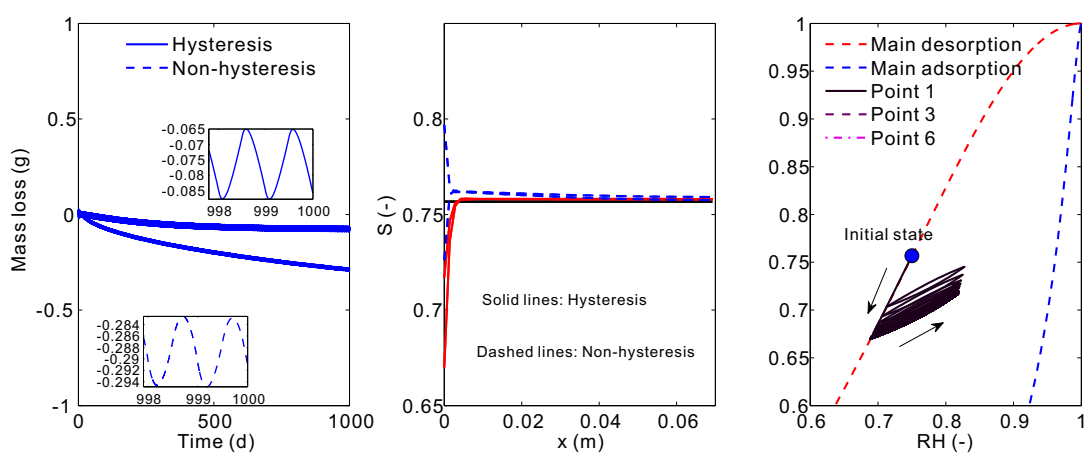

(a) The cycle duration is 1 day.
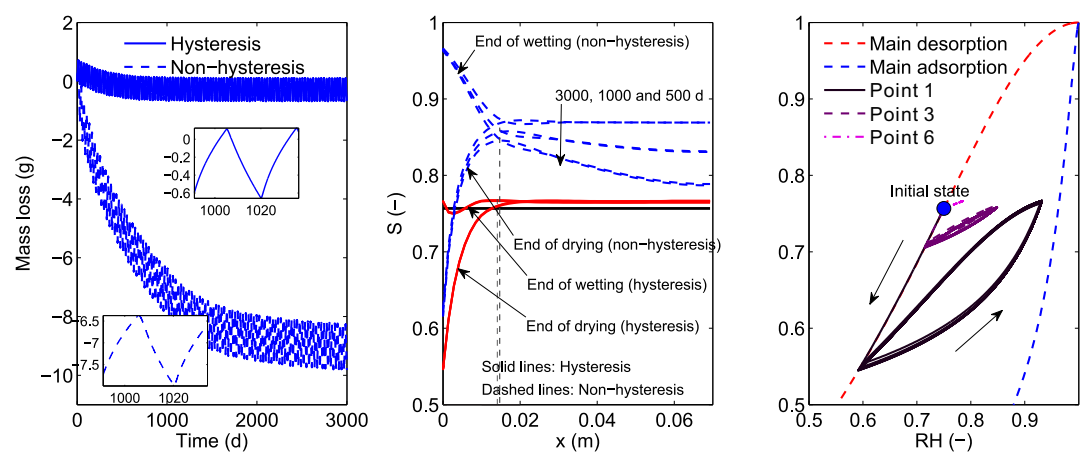

(b) The cycle duration is 30 days.
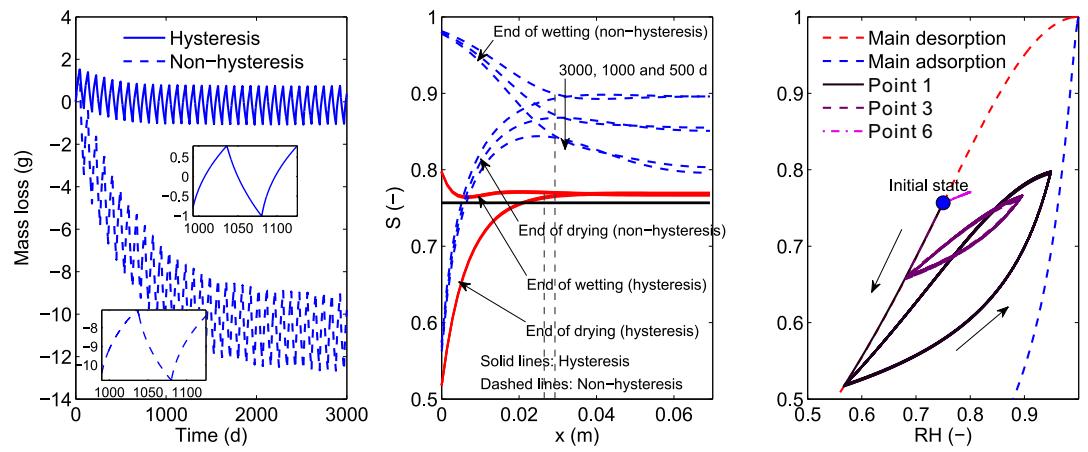

(c) The cycle duration is 90 days.

Figure 11: Simulation results of different cycle durations in the cases of non-hysteresis and hysteresis modelling by taking Paste1 as an example. The subfigures on the left-hand side show the mass loss curves. Partially enlarged figures are also provided. The central subfigures show saturation profiles at the end of drying and at the end of wetting after 500, 1000 and 3000 days. The solid-black lines indicate the initial condition. The gray dashed lines show the moisture penetration depth, calculated by the method provided in section 6.4. The subfigures on the right-hand side show simulated sorption isotherms (scanning loops) at different depths. The positions of points 1, 3 and 6 in the material have been marked in Fig. 2.

\subsection{Effects of the initial step}

To perform numerical simulations, the initial position of each node on the curve RH - $S$ must be chosen. Internal RH varies a lot depending on the duration of the sealed curing period. For example, in measurements carried out by Baroghel-Bouny et.al [65] for a large variety of cementitious materials, internal RH is between $69 \%$ and $94 \%$ after a 1 -year sealed curing period. Hence, based on these data and concerning the necessity to fix the same initial RH for all the studied materials for a comparison purpose, the choice of a middle $\mathrm{RH}\left(e . g . \mathrm{RH}^{0}=75 \%\right)$ on the main desorption curve as the initial condition has been made.

The next question for a simulation purpose is whether the first step is drying or wetting. In experiments (see 

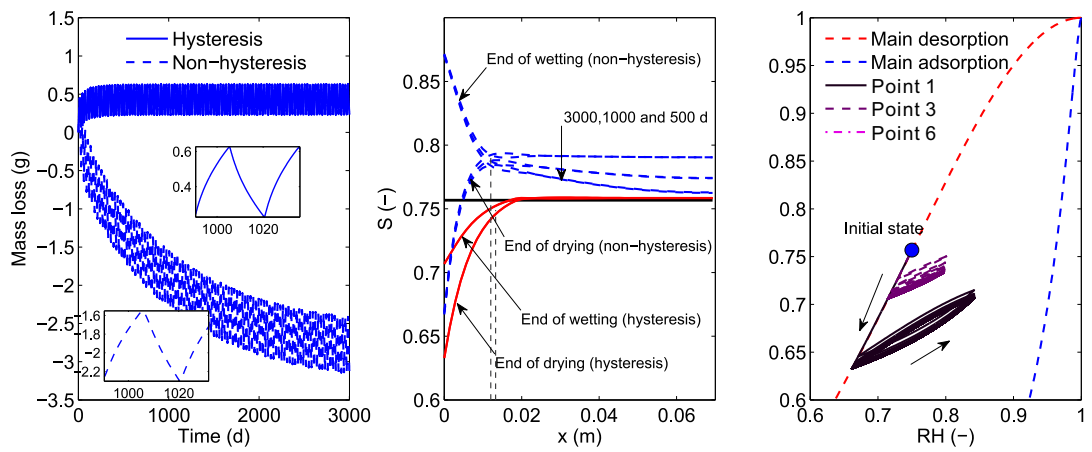

Figure 12: Simulation results in the case of a $22 \% \mathrm{RH}$ amplitude (between $64 \%$ and $86 \%$ ) by taking Paste1 as an example. The explanations of the legend are the same as in Fig. 11.

section 5.3), materials were firstly exposed to a low RH while in natural conditions external RH can be either higher or lower than initial RH. Thus, both an initial drying step or wetting step should be considered to represent real conditions. Simulations in the case of initial drying have been done in the above sections (see sections 6.1 and 6.2). In this section we will carry out simulations in the case of an initial wetting step. For a purpose of comparison, the following conditions are used: initial $\mathrm{RH}^{0}=75 \%$, 30-day cycle duration and $\mathrm{RH}$ amplitude $=44 \%(53 \%$ - $97 \%$, same conditions as the ones used in section 6.1 in the case of initial drying).
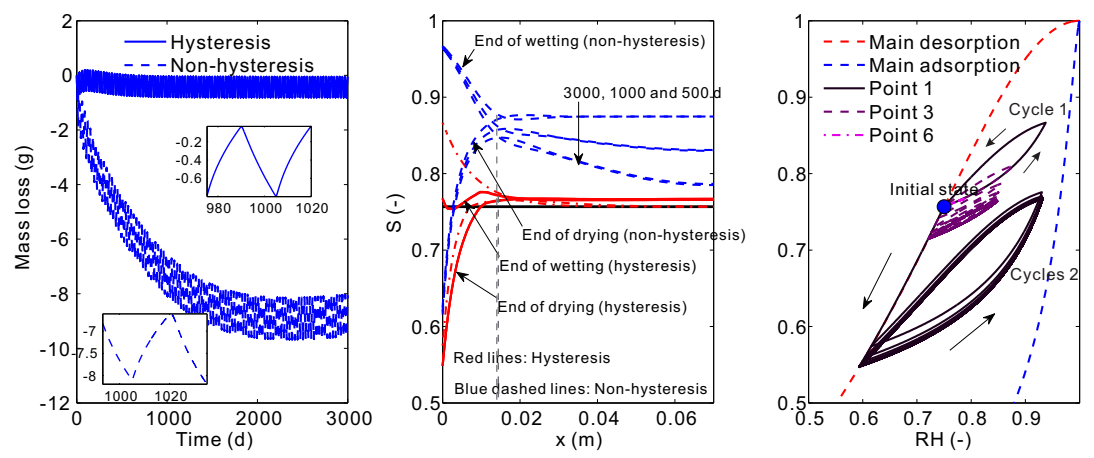

Figure 13: Simulation results in the case of initial wetting by taking Paste1 as an example. In the central subfigure, the red dash-dotted lines represent the saturation profiles at the end of drying and at the end of wetting of the first cycle. The explanations of the legend are the same as in Fig. 11.

Simulation results are presented in Fig. 13 ; they should be compared with Fig. $11 \mathrm{~b}$ in the case of an initial drying step. Firstly, the two mass loss curves in Fig. 13 are very similar to Fig. 11b. The total mass losses at the end of the simulation for the non-hysteresis modelling are very close. Secondly, saturation profiles at the end of drying and at the end of wetting after 500, 1000 and 3000 days are quite similar in Figs. 11b and 13 for both modelling methods. In fact, the difference between initial drying and initial wetting is more significant in the first cycle for the hysteresis modelling. Results simulated with initial wetting show that the saturation at the boundary in the first cycle is much higher than the following cycles (see Fig. 13). The scanning loop of the first cycle is far above the scanning loops of the following cycles (see Cycle 1 and Cycle 2 in the right-hand side subfigure of Fig. 13).

\subsection{Analysis of the moisture penetration depth}

As mentioned in the introduction, the penetration depth $x_{p}$ is an important factor to evaluate the durability of concrete structures submitted to a marine environment since $x_{p}$ is related to the depth that ions can reach into the material. Beyond $x_{p}$, it can be considered that the concentration of ions is not affected by the external ions concentration variations. To determine this depth, two recommendations have been proposed by Arfvidsson [12].

(1). In a simulation after a number of drying and wetting cycles, there must be a part of the material with a constant 
saturation that cannot be disturbed by the variations of RH at the boundary. Let's name this saturation as the undisturbed saturation, $S_{\text {und }}$ (see Fig. 14).

(2). When the undisturbed saturation is reached, this means that the saturation profile at the end of drying (and wetting) is the same for the following cycles. This also implies that the mass loss curve reach a mass equilibrium state. The moisture penetration depth $x_{p}$ is defined as the depth where the saturation difference $(\Delta S)$ between the end of drying and the end of wetting is equal to $1 \%$ (see Fig. 14).

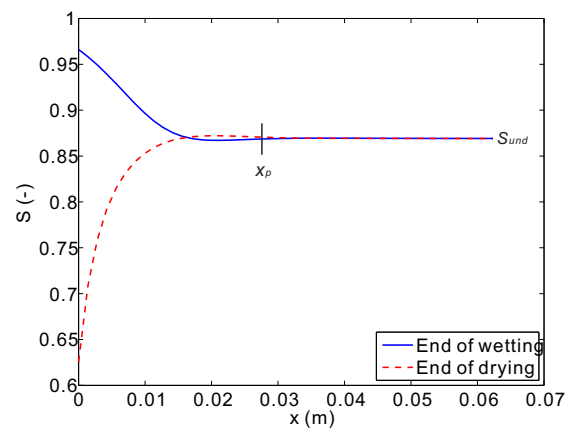

Figure 14: Definitions of the undisturbed saturation $S_{\text {und }}$ and the penetration depth $x_{p}$ after a given number of cycles.

To investigate $x_{p}$, the environmental condition, including the drying and wetting cycle duration and the RH amplitude, and the initial condition have to be determined. In this study, the cycle duration varies between 1 day and 90 days. The RH amplitude is between $44 \%\left(\mathrm{RH}^{\max }=97 \%, \mathrm{RH}^{\min }=53 \%\right)$ and $14 \%\left(\mathrm{RH}^{\max }=82 \%, \mathrm{RH}^{\min }=68 \%\right)$. The initial condition should be determined carefully. Arfvidsson [12] reported that $S_{\text {und }}$ is not related to the initial condition, but the initial condition can affect the number of cycles when $S_{\text {und }}$ is reached. In other words, if the initial $S$ is very close to $S_{u n d}, x_{p}$ can be determined in a small number of cycles. However, in our simulations, we found that this assumption is only valid in the case of non-hysteresis modelling. More discussions will be presented below. Thus, for all following simulations, the initial condition is fixed at $\mathrm{RH}^{0}=75 \%$ as in previous calculations (see sections 6.1 and 6.2).

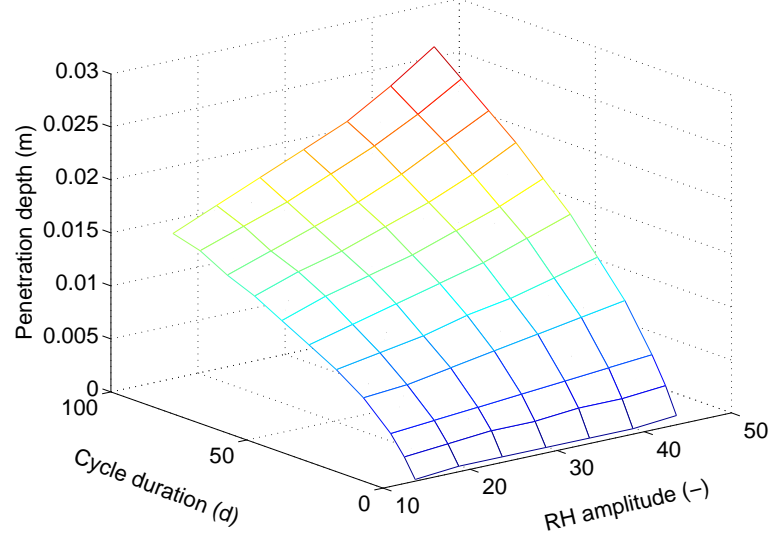

(a) Non-hysteresis modelling.

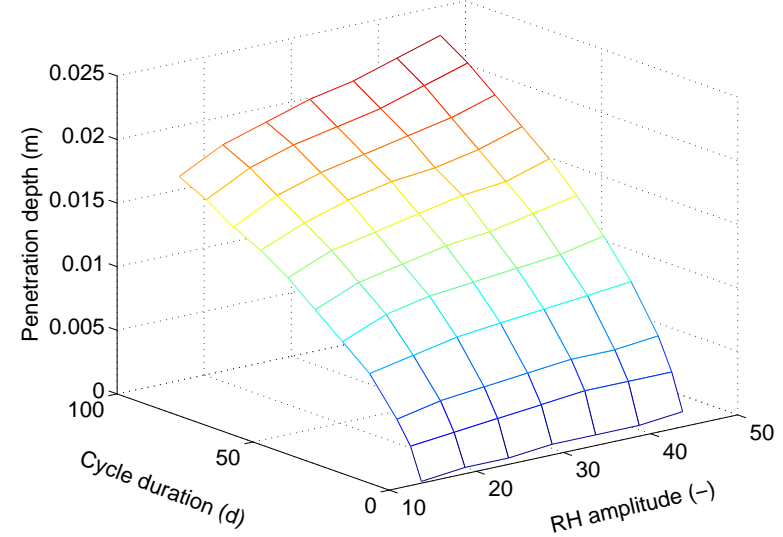

(b) Hysteresis modelling.

Figure 15: Moisture penetration depth in relation with the cycle duration and the RH amplitude for the cases of non-hysteresis and hysteresis modelling by taking Paste 1 as an example.

Simulation results show that the trends of $x_{p}$ for non-hysteresis and hysteresis modellings are quite similar (see Fig. 15). The moisture penetration depth $x_{p}$ increases with cycle duration and RH amplitude. For the small cycle durations, such as 1 day, 5 days and 10 days, even for 20 and 30 days, the differences in term of $x_{p}$ calculated by both modelling methods are very close regardless RH amplitude (less than $1 \mathrm{~mm}$ difference). Note that one example has 
been shown in Fig. 11b (see the positions of the gray dashed lines). This may be because for these cycle durations repeated drying and wetting cycles only affect moisture transport in the part near the surface of the material. Nevertheless, the differences in $x_{p}$ increase with cycle duration and RH amplitude (see the gray dashed lines in Fig. 11c). For the simulations with a 90-day cycle duration and 44\% RH amplitude, Fig. 15 shows that the $x_{p}$ difference between both modellings rises to $4 \mathrm{~mm}$ ( $24 \mathrm{~mm}$ for the hysteresis modelling and $28 \mathrm{~mm}$ for the non-hysteresis modelling). On the whole $x_{p}$ increases more sharply with cycle duration and RH amplitude for the non-hysteresis modelling than for the hysteresis modelling. This implies that the non-hysteresis modelling may overestimate $x_{p}$ for large cycle durations and large RH amplitudes. This conclusion can help for the design of durability models used to predict service life in the case of cyclic boundary conditions.

To analyze the influence of initial conditions on $x_{p}$, simulations have been performed for five different initial conditions ; results are provided in Fig. 16. For the higher $\mathrm{RH}^{0}$ value $(=85 \%$ and $80 \%)$, the predicted penetration depth is almost the same with the one obtained with the initial condition $\mathrm{RH}^{0}=75 \%$, while for lower $\mathrm{RH}^{0}(=65 \%$ and 70\%) $x_{p}$ is lower regardless the cycle duration. This conclusion can help to choose relevant initial condition for modelling. This indicates that choosing a high initial RH value (e.g. 80\%) can get a more stable $x_{p}$ curve than choosing lower initial RH (e.g. 70\%). For most cases (except high performance materials maybe) internal RH after self-desiccation seems satisfactory [65].

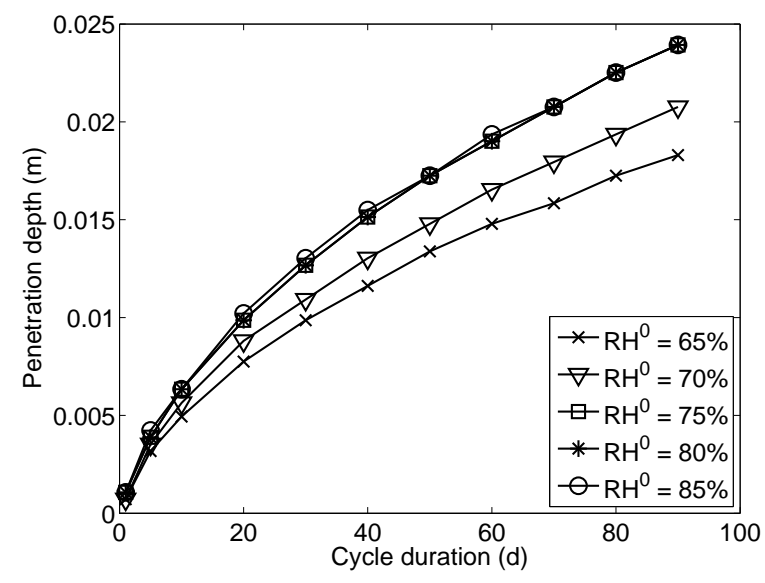

Figure 16: Comparisons of $x_{p}$ for different initial conditions and cycle durations calculated by using Mualem Model II [34]. The RH amplitude is $44 \%$.

\section{Conclusions}

In this study, hysteresis models have been coupled with a moisture transport model to simulate drying and wetting cycles. Simulations in the case of the non-hysteresis have also been performed. Based on experimental verifications and comparisons for different simulation conditions, the following conclusions can be drawn.

(1). The proposed method to implement hysteresis models into moisture transport models has a high applicability. The method can be used for both conceptual and empirical models. Two hysteresis indexes $U$ and $V$ have been introduced. The hysteresis index $U$ records the drying and wetting history of each node; it is very useful for hysteresis modelling because of its strong sorption history-dependence.

(2). Comparisons with measured mass loss curves and saturation profiles for three cement pastes show that modelling taking hysteresis into account explicitly provides better results than non-hysteresis modelling. It is principally because hysteresis models can predict a RH - $S$ relation closer to real conditions of the material, especially in the vicinity of the surface directly exposed to variations of RH (order of magnitude of the concrete cover thickness, i.e. $3 \mathrm{~cm}$ ) 
(3). Among hysteresis models, results simulated by using Mualem Model II (conceptual model) match experimental data much better than improved Rubin's model (empirical model). This is largely because improved Rubin's model provides non-physical scanning loops, characterized by the so-called "pumping error" generally observed with empirical models. Thus, Mualem Model II could be recommended for modelling of moisture transport under varying boundary conditions.

(4). Comparisons with different cycle durations reveal that smaller cycle durations cause smaller differences between non-hysteresis and hysteresis modellings. The differences increase with cycle duration. At the same time, it also shows that long term simulations cause larger errors than short term simulations. The errors simulated by the nonhysteresis modelling also increase with RH amplitude; therefore, in the situation with small cycle duration, short term and small RH amplitude, the non-hysteresis modelling is still applicable.

(5). For long term simulations, different initial steps (initial drying and initial wetting) do no show significant differences in mass loss curves and saturation profiles. The differences only occur for the first cycle in the case of hysteresis modelling.

(6). From a practical point of view, one important factor is the moisture penetration depth $x_{p}$ under periodic boundary conditions. For non-hysteresis modelling, this study confirmed that $x_{p}$ is related to cycle duration and RH amplitude, but not to initial condition. But for hysteresis modelling, the initial condition has clearly an influence on $x_{p}$. If initial RH is lower, calculated $x_{p}$ is also lower. So, the use of hysteresis modelling to estimate the moisture penetration depth has to carefully examine the initial condition which should be more or less close to the internal RH after self-dessication.

(7). Comparisons of $x_{p}$ reveal that non-hysteresis modelling may overestimate $x_{p}$ in the case of long cycle durations and large RH amplitudes.

(8). According to the number of comparisons provided in this study, it is clear that if the simulation cannot take hysteretic effects into account, the cumulative errors associated with simulation time will become significant and unavoidable.

The above conclusions are only based on results obtained on a cement paste (Paste1, $c f$. Table 1). For the future study, more cementitious materials (e.g. mortars and concretes) will be used to verify the proposed modelling method and to refine the above conclusions. Moreover the equation used to assess the relative permeability (VGM model) was initially proposed for granular media and soils. Relevant models, which are specifically developed for cementitious materials $[61,66]$, will be considered in next researches.

\section{Acknowledgement}

The research leading to these results has received funding from the European Union Seventh Framework Programme (FP7 / 2007-2013) under grant agreement 264448.

\section{References}

[1] M. Mainguy, O. Coussy, V. Baroghel-Bouny, Role of air pressure in drying of weakly permeable materials, Journal of Engineering Mechanics 127 (2001) 582-592.

[2] K. Hong, R. Hooton, Effects of cyclic chloride exposure on penetration of concrete cover, Cement and Concrete Research 29 (1999) 1379-1386.

[3] O. Coussy, Mechanics and physics of porous solids, John Wiley \& Sons, Ltd, United Kingdom, 2010.

[4] V. Baroghel-Bouny, Water vapour sorption experiments on hardened cementitious materials. Part I: Essential tool for analysis of hygral behaviour and its relation to pore structure, Cement and Concrete Research 37 (3) (2007) $414-437$. 
[5] J. Arfvidsson, J. Claesson, Isothermal moisture flow in building materials: modelling, measurements and calculations based on kirchhoff's potential, Building and Environment 35 (2000) 519-536.

[6] U. Nyman, P. Gustafsson, B. Johannesson, R. Hagglund, A numerical method for the evaluation of non-linear transient moisture flow in cellulosic materials, International Journal for Numerical Methods in Engineering 66 (2006) 1859-1883.

[7] B. Johannesson, M. Janz, A two-phase moisture transport model accounting for sorption hysteresis in layered porous building constructions, Building and Environment 44 (2009) 1285-1294.

[8] B. Johannesson, U. Nyman, A numerical approach for non-linear moisture flow in porous materials with account to sorption hysteresis, Transport in Porous Media 84 (2010) 735-754.

[9] F. Preisach, Uber die magnetische Nachwirkung, Z. Physik 94 (1935) 277-302.

[10] I. D. Mayergoyz, Mathematical models of hysteresis and their application, Elsevier, New York, USA, 2003.

[11] H. Derluyn, D. Derome, J. Carmeliet, E. Stora, R. Barbarulo, Hysteretic moisture behavior of concrete: Modelling and analysis, Cement and Concrete Research 42 (2012) 1379-1388.

[12] J. Arfvidsson, Moisture penetration depth for periodically varying relative humidity at the boundary, Nordic Journal of Building Physics 2 (1999) 75-80.

[13] IUPAC, Recommandations, Pure Appl. Chem. 57 (1985) 603.

[14] IUPAC, Recommandations, Pure Appl. Chem. 66 (1994) 1739.

[15] C. Burgess, D. Everett, S. Nuttall, Adsorption hysteresis in porous materials, Pure Appl. Chem. 57 (1989) 18451852.

[16] J. Carmeliet, S. Roels, Determination of the isothermal moisture transport properties of porous building materials, Journal of Thermal Envelope and Building Science 24 (3) (2001) 183-210.

[17] S. Poyet, j. . C. v. . . n. . p. . . y. . Sébastien Charles, title $=$ Temperature dependence of the sorption isotherms of cement-based materials: Heat of sorption and Clausius-Clapeyron formula.

[18] Q. Zeng, D. Zhang, H. Sun, j. . M. v. . p. . y. . Kefei Li, title = Characterizing pore structure of cement blend pastes using water vapor sorption analysis.

[19] A. Kumar, S. Ketel, K. Vance, T. Oey, N. Neithalath, G. Sant, Water vapor sorption in cementitious materials measurement, modeling and interpretation, Transport in Porous Media 103 (2014) 69-98.

[20] F. Brue, C. A. Davy, F. Skoczylas, N. Burlion, j. . C. v. . . p. . y. . Xavier Bourbone, title = Effect of temperature on the water retention properties of two high performance concretes.

[21] H. Ranaivomanana, J. Verdier, A. Sellier, X. Bourbon, Toward a better comprehension and modeling of hysteresis cycles in the water sorption-desorption process for cement based materials, Cement and Concrete Research 41 (2011) 817-827.

[22] V. Kocherbitov, j. . T. v. . . p. . . y. . L Lars Wadsö, title = A desorption calorimetric method for use at high water activities.

[23] M. Wu, B. Johannesson, j. . C. v. . p. . . y. . Mette Geiker, title = A study of the water vapor sorption isotherms of hardened cement pastes: Possible pore structure changes at low relative humidity and the impact of temperature on isotherms.

[24] M. Wu, B. Johannesson, j. . C. v. . p. . . y. . Mette Geiker, title = Application of water vapor sorption measurements for porosity characterization of hardened cement pastes. 
[25] E. P. Barrett, L. G. Joyner, P. P. Halenda, The determination of pore volume and area distributions in porous substances. I. Computations form nitrogen isotherms, Journal of the American Chemical Society 71 (1951) 373-380.

[26] Z. Zhang, M. Thiery, V. Baroghel-Bouny, A review and statistical study of existing hysteresis models for cementitious materials, Cement and Concrete Research 57 (2014) 44-60.

[27] L. Néel, Théorie des lois d'aimantation de lord rayleigh, Cahiers de Physique 13 (1943) 18-30.

[28] D. H. Everett, A general approach to hysteresis - Part 3: A formal treatment of the independent domain model of hysteresis, Transactions of the Faraday Society 50 (1954) 1077-1096.

[29] D. H. Everett, A general approach to hysteresis - Part 4: An alternative formulation of the domain model, Transactions of the Faraday Society 51 (1955) 1551-1557.

[30] X. S. Li, Modelling of hysteresis response for arbitrary wetting-drying paths, Computers and Geotechnics 32 (2005) 133-137.

[31] C. Wei, M. M. Dewoolkar, Formulation of capillary hysteresis with internal state variables, Water Resources Research 42 (2006) W07405.

[32] H. Huang, Y. Tan, C. Liu, C. Chen, A novel hysteresis model in unsaturated soil, Hydrological Processes 19 (2005) 1653-1665.

[33] A. D. Werner, D. A. Lockington, Artificial pumping errors in the Kool-Parker scaling model of soil moisture hysteresis, Journal of Hydrology 325 (2006) 118-133.

[34] Y. Mualem, A conceptual model of hysteresis, Water Resources Research 10 (3) (1974) 514-520.

[35] J. R. Philip, Similarity hypothesis for capillary hysteresis in porous materials, Journal of Geophysical Research 69 (1964) 1553-1562.

[36] J. Rubin, Numerical method for analyzing hysteresis-affected, post-infiltration redistribution of soil moisture, Soil Science Society of American Process 31 (4) (1967) 13-290.

[37] J. Selih, A. C. M. Sousa, T. W. Bremner, Moisture transport in initially fully saturated concrete during drying, Transport in Porous Media 24 (1996) 81-106.

[38] C. Skaar, J. F. Siau, Moisture transport in initially fully saturated concrete during drying, Wood Science and Technology 15 (1981) 101-112.

[39] M. Lebeau, j. . W. y. . J.-M. Konrad, title = A new capillary and thin film flow model for predicting the hydraulic conductivity of unsaturated porous media.

[40] M. Goyeneche, D. Lasseux, D. Bruneau, A film-flow model to describe free water transport during drying of a hygroscopic capillary porous medium, Transport in Porous Media 48 (2002) 125-158.

[41] V. Baroghel-Bouny, Water vapour sorption experiments on hardened cementitious materials. Part II: Essential tool for assessment of transport properties and for durability prediction, Cement and Concrete Research 37 (2007) 438-454.

[42] Z. Zhang, M. Thiéry, V. Baroghel-Bouny, Analysis of moisture transport in cementitious materials and modelling of drying-wetting cycles, International Conference: Numerical Modeling Strategies for Sustainable Concrete Structures, by The French Association of Civil Engineering (AFGC), Aix-en-Provence, France, 2012.

[43] M. T. van Genuchten, A closed-form equation for predicting the hydraulic conductivity of unsaturated soils, Soil Science Society of America Journal 44 (1980) 892-898. 
[44] S. D. Pont, F. Meftah, B. A. Schrefler, Modeling concrete under severe conditions as a multiphase material, Nuclear Engineering and Design 241 (2011) 562-572.

[45] M. T. Nguyen, Modélisation des couplages entre hydratation et dessiccation des matériaux cimentaires à l'issue du décoffrage, Ph.D. thesis, ENPC (September 2009).

[46] M. Azenha, K. Maekawa, T. Ishida, R. Faria, Drying induced moisture losses from mortar to the environment. Part II: numerical implementation, Materials and Structures 40 (2007) 813-825.

[47] M. A. Celia, E. T. Bououtas, R. L. Zarba, A general mass-conservative numerical solution for the unsaturated flow equation, Water Resources Research 26 (1990) 1483-1496.

[48] R. W. Gillham, A. Klute, D. F. Heermann, Measurement and numerical simulation of hysteretic flow in a heterogeneous porous medium, Soil Sci. Soc. Am. J. 43 (1979) 1061-1067.

[49] G. Villain, M. Thiery, Gammadensimetry: A method to determine drying and carbonation profiles in concrete, NDT \& E International 39 (2006) 328-337.

[50] R. Millington, Gas diffusion in porous media, Science 130 (1959) 100-102.

[51] M. Thiéry, P. Belin, V. Baroghel-Bouny, M. D. Nguyen, Modelling of isothermal drying process in cementitious materials - Analysis of the moisture transfer and proposal of simplified approaches, in: Proceedings of 3rd International Conference on Coupled T-H-M-C Processes in Geo-systems, 571-581, Polytech Lille, France, 2008.

[52] V. Papadakis, C. Vayenas, M. Fardis, Physical and chemical characteristics affecting the durability of concrete, ACI Materials Journal 8 (1991) 186-196.

[53] A. Poulovassilis, The effect of hysteresis of pore-water on the hydraulic conductivity, Journal of Soil Science 20 (1969) 52-56.

[54] Y. Mualem, Hysteretical models for prediction fo the hydraulic conductivity of unsaturated porou media, Water Resources Research 12 (1976) 1248-1254.

[55] G. C. Topp, E. E. Miller, Hysteretic moisture characteristics and hydraulic conductivities for glass-bead media, Soil Science Society of America Journal 30 (1966) 156-162.

[56] G. C. Topp, Soil-water hysteresis: The domain model theory extended to pore interaction conditions, Soil Science Society of America Journal 35 (1971) 219-225.

[57] A. Poulovassilis, E. E. Childs, The hysteresis of pore water: the non-independence of domains, Soil Science 112 (1971) 301-312.

[58] Q. de Jong van Lier, D. D. Neto, K. Metselaar, Modeling of transpiration reduction in van Genuchten - Mualem type soils, Water Resources Research 45 (2009) W02422.

[59] Y. Mualem, A new model for predicting the hydraulic conductivity of unsaturated porous media, Water Resources Research 12 (1976) 513-522.

[60] J. C. Parker, R. J. Lenhard, A model for hysteretic constitutive relations governing multiphase flow: 1.saturationpressure relations, Water Resources Research 23 (1987) 2187-2196.

[61] H. Ranaivomanana, J. Verdier, A. Sellier, X. Bourbon, Prediction of relative permeabilities and water vapor diffusion reduction factor for cement-based materials, Cement and Concrete Research 48 (2013) 53-63.

[62] S. Zamani, R. Kowalczyk, P. J. McDonald, The relative humidity dependence of the permeability of cement paste measured using garfield nmr profiling, Cement and Concrete Research 57 (2014) 88-94. 
[63] O. Coussy, V. Baroghel-Bouny, P. Dangla, M. Mainguy, Assessment of the water permeability of concretes from their mass loss during drying (in french), in: in: V. Baroghel-Bouny (Ed.), Transferts dans les bétons et durabilité, Special issue of Revue Française de Génie Civil, vol. 5, Hermès Science Publications, p.269-284, Paris, 2001.

[64] V. Baroghel-Bouny, M. Thiéry, F. Barberon, O. Coussy, G. Villain, Assessment of transport properties of cementitious materials. A major challenge as regards durability?, Revue European de Genie Civil 11 (2007) 671-696.

[65] V. Baroghel-Bouny, M. Mainguy, T. Lassabatere, O. Coussy, Characterization and identification of equilibrium and transfer moisture properties for ordinary and high-performance cementitious materials, Cement and Concrete Research 29 (1999) 1225-1238.

[66] C. Zhou, Predicting water permeability and relative gas permeability of unsaturated cement-based material from hydraulic diffusivity, Cement and Concrete Research 58 (2014) 143-151. 